related in $28.3 \%$, headache in $9.4 \%$, and insomnia in $7.5 \%$. No patient discontinued the drug because of adverse events. (Greenhill LL, Muniz R, Ball RR, et al. Efficacy and safety of dexmethylphenidate extended-release capsules in children with attention-deficit/hyperactivity disorder. J Am Acad Child Adolesc Psychiatry July 2006;45:817-823). (Reprints: Dr Laurence L Greenhill, New York State Psychiatric Institute, 1051 Riverside Drive, Room 2307, New York, NY 10032).

COMMENT. At a mean daily dose of $24 \mathrm{mg} /$ day, d-MPH-ER was significantly superior to placebo in the treatment of ADHD. The mean dose of d-MPH-ER found effective is equivalent to a $50 \mathrm{mg} /$ day dose of racemic methylphenidate.

\title{
BEHAVIORAL PREDICTORS OF SUBSTANCE-USE INITIATION IN ADOLESCENTS WITH AND WITHOUT ADHD
}

Substance-use initiation was examined in 28 healthy adolescents and 50 with attention-deficit/hyperactivity disorder, followed longitudinally for 4 years at the National Institute of Mental Health, Bethesda, MD; National Institute on Drug Abuse, Baltimore, MD; and Neuropsychiatric Institute, Los Angeles, CA. Usage of tobacco, alcohol, and marijuana, substances most commonly reported, was not influenced by ADHD, ADHD and comorbid conduct disorder, or ADHD and depressive/anxiety. Among behavioral measures assessed at study entry, aggression was associated with tobacco smoking and marijuana use, and impulsivity with alcohol use. The severity of substance-use, indicated by the number of substances used, was correlated with and predicted by early aggressive behavior. (Ernst M, Luckenbaugh DA, Moolchan ET, et al. Behavioral predictors of substance-use initiation in adolescents with and without attention-deficit/hyperactivity disorder. Pediatrics June 2006;117:2030-2039). (Respond: Monique Ernst MD, PhD, Mood and Anxiety Disorders Program, National Institute of Mental Health, 15K North Dr, Room 118, MSC 2670, Bethesda, MD 20892).

COMMENT. A risk of using or abusing drugs in adolescence is a common concern of parents of children with ADHD, when discussing methylphenidate or other stimulant medication. The above report confirms previous studies showing that, except for impulsivity and alcohol, ADHD does not increase the risk of illicit substance-use or abuse in adolescence. A study at the Massachusetts General Hospital found drug abuse in $15 \%$ of 140 ADHD adolescents and the same frequency in 120 normal control subjects, followed for 4 years (Biederman J et al. 1997). The risk of alcohol and drug abuse was increased in patients with conduct or bipolar disorders, but not oppositional defiant disorder (ODD), major depression or anxiety. ODD, uncomplicated by conduct disorder did not predict drug abuse. In contrast to children and adolescents, adults with ADHD are more susceptible to drug abuse, especially if they have not previously received treatment for ADHD in childhood. Prescribed stimulant treatment for ADHD is found to decrease drug craving in adults with comorbid ADHD and drug abuse and to improve functioning (Horner BR, Scheibe KE, 1997). Psychosocial intervention and appropriate medications at an early age are important in prevention of substance abuse disorders in adults with pervasive ADHD. (Millichap JG. Attention Deficit Hyperactivity and Learning Disorders. Chicago, PNB Publishers, 1998) 